\title{
Electroconvulsive Therapy (ECT) in Sudan, Probing Differences between Africa and the West
}

\author{
Abdelgadir H. Osman 1* ${ }^{*}$ Zohair Elbagir Ali², Khalied Abdel Kareem², Nosiba Suleiman² \\ ${ }^{1}$ MRCP1, MRCPsych, Head Department of Psychiatry, Faculty of Medicine, University of Khartoum, Khartoum, \\ Sudan \\ ${ }^{2}$ Sudan National Medical Council, Khartoum, Sudan \\ Email: ${ }^{*}$ abdelgadir1159@yahoo.com
}

Received 5 August 2015; accepted 12 September 2015; published 15 September 2015

Copyright (C) 2015 by authors and Scientific Research Publishing Inc.

This work is licensed under the Creative Commons Attribution International License (CC BY). http://creativecommons.org/licenses/by/4.0/

(c) (i) Open Access

\begin{abstract}
It is a retrospective qualitative study of all patients that had received ECT treatment in Khartoum National Psychiatric Hospitals in the period between January 2010 and December 2010 with special reference to indications, side effects, and outcome using the same outcome criteria used by the royal college of Psychiatrists (UK) for modified audit format. 85\% from 269 of overall Sudanese patients who had received ECT showed remarkable clinical response, with no major adverse side effects. Interestingly, the response rate was over $90 \%$ for patients with mania spectrum diagnosis. $85 \%$ of our patients were under the age of 40 . Two thirds of the patients, who received ECT, were male. The main indication for ECT (45\%) was mania, while depression and mixed affective states constituted less than $25 \%$ of the sample. Conclusion: In comparison to the West, ECT plays a major role in the treatment of mania and manic spectrum disorders in Africa.
\end{abstract}

\section{Keywords}

Electroconvulsive Therapy (ECT), Affective Disorders, Sudanese Patients

\section{Background}

Although Electroconvulsive Therapy (ECT) has been available for more than 70 years, only few researches were published referring to its indication and outcome in Africa [1]. It is also known that, electroconvulsive therapy (ECT) is being used quite frequently among bipolar patients in developing countries; nonetheless, very little data

${ }^{*}$ Corresponding author. 
are available with regard to its effectiveness from the developing countries [1] [2].

Electroconvulsive therapy (ECT) was the mainstay of treatment for both manic and depressive phases of Bipolar Affective Disorder (BPAD) long before the introduction of neuroleptics and mood stabilisers. However, over the years with the evolution of old and new generation of neuroleptics and mood stabilisers, compounded with the controversies surrounding the use of ECT Psychiatrists in different part of the world have acknowledged the distortions caused by the media, reinforced by the malign influence of bodies such as the Citizen's Commission on Human Rights that have long campaigned against psychiatry in all its aspects, have produced so much dread and suspicion that we have moved very quickly to a point where psychiatrists are under great pressure to withhold what is often a life-saving treatment, and where patients who could benefit are too afraid to seek help of any sort [1]-[3].

This has curbed and reduced the use of ECT remarkably in the case of mania and restricted the use of ECT only to severe depression with psychomotor retardation, refractory depression and where there is serious risk of health or suicide [3] [4].

And in the case of mania both the Royal college of psychiatrist recommendations and that of NICE have curbed the use of ECT to severe mania associated with, life-threatening physical exhaustion and treatment resistance mania that has not responded to the treatment of choice which are mood stabilisers and an antipsychotic drug, yet, this can only place the psychiatrist under huge scrutiny and on a defensive position [3]-[5].

Nonetheless, Mukherjee \& Sackeims, 50 years review of use of ECT in mania concluded that ECT is an effective and safe treatment for acute mania. Remission of mania following ECT reflects a primary therapeutic effect rather than a secondary sequence of an ECT induced organic brain syndrome [6].

However, variation in the use of ECT has long been acknowledged by several national and international auditing bodies in UK, USA and different parts of Europe [7].

In the Royal College survey of selected districts in England, it was shown that the variation in the ECT use was more than 10 fold between an inner city London district and other areas. However, in Scotland the variation was noted to be around 18 fold. Interestingly, even in the same Hospital this variation had been noted to be noticeable between one psychiatrist to another within the same health authority using the same criteria. Glen and Scott (2000) reported an 18 fold difference in use of ECT between 11 general adult psychiatric teams within a single Edinburgh Teaching Hospital [8]-[10].

The overall use of ECT, which has been reported by several studies, is in declining in the West and USA. The use of ECT is declining in the UK. In 1985 there were 137,940 administrations through English National Health Service. In 1991 this figure had fallen to 105,466. The annual number of treatments fell even further by 1999 to an estimated 65,930, equivalent to 5.8 patients per 100,000 total population. Between 1992 and 1997, the rate of ECT use in Edinburgh, UK, fell from 2.85 to 1.65 treatments per 1000 population served, mostly because of a $58 \%$ reduction in the number of recipients aged 18 - 65 years (Glen \& Scott, 1999). In Wales the estimated annual rate fell from 39 to 22 patients per 100,000 between 1990 and 1996 (Duffett et al., 1999). Likewise indications for ECT's treatment have changed over the time and were clearly shown in earlier Royal College National audits of ECT at different regions in UK [9]-[11].

Therefore this article addresses some of these variations in the use of ECT from a developing country's perspective, the indication of use of ECT as an example of an African country (Sudan main national psychiatric hospital in the capital city). It will also addresses relevant issues of outcome of ECT treatment, side effects with special reference to cognitive impairments and any other serious side effects reported during the use of ECT.

\section{Methods and Material}

\subsection{Study Design}

It is a descriptive retrospective Audit study for all patients admitted to Khartoum National Psychiatric Hospitals in the period between $1^{\text {st }}$ January 2010 to December 2010. The total number of patients that had received in-patient hospital treatment in the period between, January 2010-December 2010 were 1795 (998 were males, and 797 were females), of whom 269 patient required ECT treatment, constituting 15\%, of the total admission list. 153 (56.9\%) were males, 116 females (43.1\%).

The study was approved and given ethical clearance by the Faculty of Medicine Research Review Committee. Permissions were also obtained from relevant hospital authorities.

We designed a study tools for recording information in a format simulating the questionnaire used by the 
Royal College Audit in Wales 1999 National Audit recording details social demographic information of patients, clinical profile and diagnosis using ICD10 criteria [12] [13].

Data were collected by three trained psychiatric medical registrars and supervised by the head of the department of psychiatry university of Khartoum. All research team were cited on the study, and they approved the final manuscript.

Medical entries about patients response to ECT, benefit or otherwise adverse effect and cognitive impairment would be recorded by, a medical Doctor of the clinically responsible teams.

All patients' clinical records were thoroughly studied by the research team, to drive required information. In less than a quarter of the patients where diagnosis were not clearly noted, detailed reference to the patients clinical notes were made and further discussions were held with their treating psychiatrists to verify diagnosis.

Clinical outcome results were recorded together with any adverse side effects especially in reference to cognitive and memory impairments. [14].

Improvement in clinical symptoms assessed using Global Clinical Impression (GLI) by relevant treating team

Statistical Analysis:

Data were analyzed using computer software program, the statistical package for social sciences (SPSS, version 15) [15].

The results were expressed in percentage of response rates from the total number of cases, and, relative to the specific diagnosis.

\subsection{Electroconvulsive Therapy (ECT) Machine and Administration}

ECT is administered on inpatient and occasionally outpatient basis. The consultant-in-charge of the patient makes the final decision about administering ECT after discussion with the patient, his/her relatives and the clinical team. The decision for administering ECT is taken individually in each patient, based on a review of his or her clinical status and previous treatment history. However, no mandatory guidelines regarding administration of ECT are followed. If ECT is clinically indicated, a written informed consent is sought from patients and their relatives. Consenting patients undergo physical assessments and investigations as required. If found fit, the patient is given brief-pulse, bilateral, mostly unmodified ECT in most of psychiatric Hospitals outside the Capital city. There is increasing trends for administering modified ECT, in National psychiatric Hospitals at the Capital city Khartoum, and the private psychiatric Units.

ECT, is usually administered by trained senior nurses given a working title of medical assistants, however in the Capital city, where there is a national psychiatric training scheme, a medical registrar will take care of administering the ECT.

Ectron 5 \& 6 UK manufactured machines are used. Patients were given atropine premedication, suxamethonium chloride (scoline) or Propofol are used as muscle relaxant and for induction of generalized anaesthesia, in most of main psychiatric Hospitals in the Capital city. One of three main psychiatric Hospitals, still uses $20 \mathrm{mg}$ intravenous diazepam to induce sleep (drowsiness state) and reduce the strength of the seizures, of not fully modified ECT treatment i.e. no generalized anaesthesia is used.

Patients were anesthetized by specialized medical doctor in anaesthesia, with full support of oxygen machines and DC shock machines for cardiac arrests. After recovery patients were escorted back to their wards.

\section{Results}

Out of the 269 patients, who had received ECT treatment, 153 (56.9\%) were male, 116 female (43.1\%), Table 1, with an average age of 30.32 standard deviation) (ST 11.375), Table 2.

\subsection{Clinical Profile of Patients}

$80 \%$ of patients treated with ECT were under the age of 40 with less than $10 \%$ of the entire sample over the age of 50 years of age. $43.8 \%$ of those who received ECT were suffering from mania whilst only $18 \%$ were suffering from severe to refractory depression. Table 3 gives the detailed analysis of the various indications cited for ECT treatment.

$71.7 \%$ of the sample received ECT for the first time whilst 28.2 had received ECT before. 224 patients (81.8\%) reported complete recovery after ECT and 42 patients (15.3\%) shown partial improvement. Only 3 
Table 1. Distribution of patients who received ECT.

\begin{tabular}{ccc}
\hline & Number & $\%$ \\
\hline Male & 153 & $56.9 \%$ \\
Female & 116 & $43.1 \%$ \\
Total & $\mathbf{2 6 9}$ & $\mathbf{1 0 0 \%}$ \\
\hline
\end{tabular}

Table 2. Distribution of age groups in the sample.

\begin{tabular}{ccc}
\hline Age group & Frequency & Percentage (\%) \\
\hline Less than 20 & 36 & $13.4 \%$ \\
$20-29$ & 116 & $43.1 \%$ \\
$30-39$ & 60 & $22.3 \%$ \\
$40-49$ & 32 & $11.9 \%$ \\
More than 50 & 25 & $9.3 \%$ \\
Total & $\mathbf{2 9 6}$ & $\mathbf{1 0 0 \%}$ \\
\hline
\end{tabular}

Table 3. Shows ECT indications of diagnosis.

\begin{tabular}{ccc}
\hline Depression & Frequency & Percent \\
Mania & 49 & $18.2 \%$ \\
Schizophrenia & 118 & $43.8 \%$ \\
Schizoaffective disorder & 41 & $15.2 \%$ \\
Mixed Affective Disorder & 24 & $8.0 \%$ \\
Puerperal psychosis & 10 & $3.7 \%$ \\
Delusional Disorder & 11 & $4.0 \%$ \\
Organic psychosis & 3 & $1.1 \%$ \\
Total & 13 & $4.8 \%$ \\
\hline
\end{tabular}

patients that is $1.1 \%$ reported no improvement whatsoever. However, more patients with mania and affective disorder had shown complete or partial improvement with ECT compared to those with Schizophrenia or Schizoaffective Disorder (Table 4).

Interestingly all patients, that were given diagnosis of organic psychosis had shown full recovery following ECT treatment (Table 4 and Table 5).

$13.8 \%$ of our samples were given ECT as a life saving procedure, $51.4 \%$ due to failure of response to treatments with antipsychotics, mood stabilisers or antidepressants. $32 \%$ of the samples were given ECT as first choice, mostly due to high psychomotor agitation with excitement (Table 6). We noted only 3\% received ECT due to failure to respond to other forms of treatments.

\subsection{Discussion}

In comparison to similar studies conducted in the West, e.g. ECT audit in Wales 1996 and study of national audit of Scotland November 2010, the majority of our patients received ECT for mania which was nearly $42 \%$. This category only constituted around 5\% of patients given ECT (for mania) in the West. This difference is explained by the limitation of the psychiatric service in remote areas in Africa where patients would present with 
Table 4. Shows the outcome of ECT.

\begin{tabular}{ccc}
\hline Outcome & Frequency & Percent \\
\hline Complete improvement & 224 & $81.8 \%$ \\
Partial improvement & 42 & $15.3 \%$ \\
No improvement & 3 & $1.1 \%$ \\
Total & $\mathbf{2 6 9}$ & $\mathbf{1 0 0 \%}$ \\
\hline
\end{tabular}

Table 5. Cross tabulation between the diagnosis and outcome.

\begin{tabular}{ccccc}
\hline & Complete Recovery & Partial Recovery & No improvement & Total \\
\hline Depression & 45 & 4 & 0 & 49 \\
Mania & 94 & 23 & 1 & 118 \\
Schizophrenia & 30 & 10 & 1 & 41 \\
Schizoaffective & 22 & 1 & 1 & 24 \\
Mixed affective disorder & 9 & 1 & 0 & 10 \\
Puerperal Psychosis & 10 & 1 & 0 & 11 \\
Delusional Disorder & 1 & 2 & 0 & 3 \\
Organic Psychosis & 13 & 0 & 0 & 13 \\
Total & $\mathbf{2 2 4}$ & $\mathbf{4 2}$ & $\mathbf{3}$ & $\mathbf{2 6 9}$ \\
\hline
\end{tabular}

Table 6. Reason why ECT was given.

\begin{tabular}{ccc} 
Induction & Frequency & Percent \\
Emergency & 37 & $13.8 \%$ \\
First choice treatment & 86 & $32 \%$ \\
Failure of drug treatment & 138 & $51.4 \%$ \\
Last resort & 8 & $3 \%$ \\
Total & $\mathbf{2 6 9}$ & $\mathbf{1 0 0} \%$ \\
\hline
\end{tabular}

florid symptoms of mania by the time they present to the psychiatric system or brought to central psychiatric hospital in the capital city. Moreover limitation of resources makes ECT sometimes the safest choice. For example, limited number of staff levels looking after patients, as this is considerably lower in Africa. In fact, management of psychiatric patients is a shared responsibility between patients' relatives and hospital staff [16] [17].

ECT, therefore, is an effective treatment for many psychiatric disorders. Compared to the Western countries, ECT is also probably seen to reduce the duration of hospital stay in Sudan and many developing countries [18].

Nevertheless, certain trends regarding the administration of ECT among our patients, and may be in other developing countries were discernible.

Sizable minority of our patients presented with what was labelled as organic psychosis. Those patients presented with, affective like psychosis, accompanied with, hallucinations, delusions, and clouding of consciousness. The underline precipitating factors were often of organic nature, such as illicit drugs (mainly cannabis) or subsequent to tropical infectious diseases [19] [20].

Most of those patients admitted to psychiatric service with this organic psychosis would have already been treated for any underlying organic causation nonetheless continued to exhibit remarkable psychiatric symptomatology attracting a diagnosis of organic psychosis. This category of patients have shown full and complete recovery to ECT, the type of which is rarely seen in the West apart from in puerperal psychosis or drug induced 
psychosis, which displays similar psychiatric presentation.

$84 \%$ of our patients were already receiving either antipsychotic or mood stabiliser when ECT was administered and many of them were receiving a combination of both. When individual manic symptoms were considered in our study, it was noted that ECT had a substantial ameliorative effect on all the manic symptoms [21] [22].

One of the main finding of this study is the high ratio of response rate to ECT with no serious cognitive impairments following the completion of ECT courses. Similar results were noted in Sakiems review of 50 years experience of ECT treatment with acute manic episodes. Vineet Bharadwaj et al reported comparable results for acute mania in North India [23].

On the other hand only very small percentage of patient with acute mania are treated with ECT in the West and that was reflected in NICE guidelines where it recommends that ECT should only be considered for severe mania associated with life threatening physical exhaustion, treatment resistant mania that had not responded to treatment of choice (namely mood stabilising drugs plus antipsychotic drugs). Nonetheless different prospective studies revealed ECT treatment for manic patients already receiving antipsychotics not only shortened their inpatient stay but also made safe and quick recovery for patients from mania as this was noted by Sikdar et al. [24] Remarkable trend in the use of ECT in our sample is the average age of the patients that received ECT, which is less than 40 years of age. Comparable data from the West shows average age above 60 .

Two third of our sample were male. Both patients' gender and age were different trends from what were known in the west. As, two thirds of patients Audited for ECT in the West are female over 65 years of age [25].

No serious adverse effect occurred to our patients and similarly no permanent cognitive impairment had been recorded.

\section{Lesson from This Study}

However this study supports the use of ECT for acute and severe mania in under resourced developing countries provided good training and well updated ECT machines are well thought for.

\section{Limitations of the Study}

The main limitation of this study was the fact that, its a retrospective descriptive study of patients, where outcome results and similarly adverse effects were only clinically recorded. No formal, standardize measurement had been used to gauge outcome or adverse effects.

\section{Implication of This Study}

ECT remained an effective method of treatment for under resourced developing countries for Bipolar Affective Disorders patients, with severe symptoms at presentation for both depressive and manic phases. It is not only proved to be effective in treating the core symptoms but also shortened patients' stay time in hospital and requirements for administration of injectable tranquilisers to control acute psycho agitation of patient with a consequent occasional morbidity and mortality.

Future design should be based on prospective randomised clinical intervention for patients with mania taking into consideration sensitive measurements for outcome and measurements of adverse effects, especially cognitive functions.

\section{Declaration of Interest}

Non.

\section{References}

[1] Rose, L. (1977) ECT in Underdeveloped Countries. British Medical Journal, 2, 895.

[2] National Institute for Clinical Excellence (2003) Guidance on the Use of Electroconvulsive Therapy (Technology Appraisal 59, April). www.nice.org.uk/pdf/59ectfullguidance.pdf

[3] Royal College of Psychiatrists (1995) The ECT. Handbook. The Second Report of the Royal College of Psychiatrists' Special Committee on ECT (Council Report CR39). Royal College of Psychiatrists, London. 
[4] McCall, W.V. (2001) Electroconvulsive Therapy in the Era of Modern Psychopharmacology. International Journal of Neuropsychopharmacology, 4, 315-324. http://dx.doi.org/10.1017/s1461145701002437

[5] Philpot, M., Treloar, A., Gormley, N. and Gustafson, L. (2002) Barriers to the Use of Electroconvulsive Therapy in the Elderly: A European Survey. European Psychiatry, 17, 41-45. http://dx.doi.org/10.1016/s0924-9338(02)00620-X

[6] Mukherjee, S., Sackeim, H.A. and Schnur, D.A. (1994) Electroconvulsive Therapy of Acute Manic Episodes: A Review of 50 Years' Experience. The American Journal of Psychiatry, 151, 169-176. http://dx.doi.org/10.1176/ajp.151.2.169

[7] Glen, T. and Scott, A.I.F. (2000) Variation in Rates of Electroconvulsive Therapy Use among Consultant Teams in Edinburgh (1993-1996). Journal of Affective Disorders, 58, 75-78. http://dx.doi.org/10.1016/S0165-0327(99)00095-6

[8] Hermann, R.C., Dorwart, R.A., Hoover, C.W., et al. (1995) Variation in ECT Use in the United States. American Journal of Psychiatry, 152, 869-875. http://dx.doi.org/10.1176/ajp.152.6.869

[9] Glen, T. and Scott, A.I.F. (1999) Rates of Electroconvulsive Therapy Use in Edinburgh (1992-1997). Journal of Affective Disorders, 54, 81-85. http://dx.doi.org/10.1016/S0165-0327(98)00144-X

[10] Duffett, R. and Lelliott, P. (1998) Auditing Electroconvulsive Therapy. The Third Cycle. The British Journal of Psychiatry, 172, 401-405. http://dx.doi.org/10.1192/bjp.172.5.401

[11] Pippard, J. and Ellam, L. (1981) Electroconvulsive Treatment in Great Britain, 1980. Gaskell, London.

[12] Duffett, R., Siegert, R.D. and Lelliott, P. (1999) Electroconvulsive Therapy in Wales. Psychiatric Bulletin, 23, 597-601. http://dx.doi.org/10.1192/pb.23.10.597

[13] Bharadwaj, V., Grover, S., Chakrabarti, S., Avasthi, A. and Kate, N. (2012) Clinical Profile and Outcome of Bipolar Disorder Patients Receiving Electroconvulsive Therapy: A Study from North India. Indian Journal of Psychiatry, 54, 41-47.

[14] Scottish, E.C.T. (2009) Accreditation Network. Annual Report 2009: Reporting on 2008. NHS National Services Scotland.

[15] Bryman, A. and Cramer, D. (2009) Quantitative Data Analysis with SPSS 14, 15 and 16: A Guide for Social Scientists. Routledge, New York.

[16] Sikdar, S., Kulhara, P., Avasthi, A. and Singh, H. (1994) Combined Chlorpromazine and Electroconvulsive Therapy in Mania. British Journal of Psychiatry, 164, 806-810. http://dx.doi.org/10.1192/bjp.164.6.806

[17] van den Broek, W.W., de Lely, A., Mulder, P.G.H. and Bruijn, J.A. (2004) Effect of Antidepressant Medication Resistance on Short-Term Response to Electroconvulsive Therapy. Journal of Clinical Psychopharmacology, 24, 400-403. http://dx.doi.org/10.1097/01.jcp.0000130551.70878.56

[18] Brown, K.A. (2009) Unilateral and Bilateral Electroconvulsive Therapy: What Informs Scottish Psychiatrists’ Choices? Psychiatric Bulletin, 33, 95-98.

[19] Scott, A.I.F. (2005) College Guidelines on Electroconvulsive Therapy: An Update for Permissions. The Place of ECT in the Treatment of Mania.

[20] White, C. (2005) New Guidance on ECT Looks Set to Curb Its Use. Advances in Psychiatric Treatment, 11, $150-156$.

[21] Sackeim, H.A., Prudic, J., Fuller, A.R., Keilp, J., Lavori, P.W. and Olfson, M. (2007) The Cognitive Effects of Electroconvulsive Therapy in Community Settings. Neuropsychopharmacology, 32, 244-254. http://dx.doi.org/10.1038/sj.npp.1301180

[22] Dombrovski, A.Y., Mulsant, B.H., Hasket, R.F., Prudic, J., Begley, A.E. and Sackeim, H.A. (2005) Predictors of Remission after Electroconvulsive Therapy in Unipolar Major Depression. Journal of Clinical Psychiatry, 66, 1043-1049. http://dx.doi.org/10.4088/JCP.v66n0813

[23] Piolino, P., Desgranges, B. and Eustache, F. (2009) Episodic Autobiographical Memories over the Course of Time: Cognitive, Neuropsychological and Neuroimaging Findings. Neuropsychologia, 47, 2314-2329. http://dx.doi.org/10.1016/j.neuropsychologia.2009.01.020

[24] Grunze, H., Kasper, S., Goodwin, G., Bowden, C., Baldwin, D., Licht, R.W., et al. (2003) The World Federation of Societies of Biological Psychiatry (WFSBP) Guidelines for the Biological Treatment of Bipolar Disorders, Part II: Treatment of Mania. The World Journal of Biological Psychiatry, 4, 5-13. http://dx.doi.org/10.3109/15622970309167904

[25] The UK ECT Review Group (2003) Efficacy and Safety of Electroconvulsive Therapy in Depressive Disorders: A Systematic Review and Meta-Analysis. The Lancet, 361, 799-808. http://dx.doi.org/10.1016/S0140-6736(03)12705-5 